\title{
Overall survival in renal cell carcinoma after introduction of targeted therapies: a Norwegian population-based study
}

\author{
Christian Beisland ${ }^{1,2}$ \\ Tom B Johannesen ${ }^{3}$ \\ Olbjorn Klepp ${ }^{4}$ \\ Ulrika Axcrona ${ }^{5}$ \\ Knut Martin Torgersen ${ }^{6}$ \\ Jan Kowalski ${ }^{7}$ \\ Oddvar Solli6 \\ Rickard Sandin ${ }^{8}$ \\ Jan Oldenburg 99 \\ 'Department of Urology, \\ Haukeland University Hospital, \\ ${ }^{2}$ Department of Clinical Medicine, \\ University of Bergen, Bergen, \\ ${ }^{3}$ Department of Registration, \\ Cancer Registry of Norway, Oslo, \\ ${ }^{4}$ Department of Oncology, Ålesund \\ Hospital, Ålesund, ${ }^{5}$ Department of \\ Pathology, Oslo University Hospital, \\ the Norwegian Radium Hospital, \\ Oslo, ${ }^{6}$ Pfizer AS, Oslo, Norway; \\ ${ }^{7} \mathrm{JK}$ Biostatistics AB, Stockholm, ${ }^{8}$ Pfizer \\ $A B$, Sollentuna, Sweden; ${ }^{9}$ Department \\ of Oncology, Akershus University \\ Hospital, Lørenskog, ${ }^{10}$ Medical Faculty, \\ University of Oslo, Oslo, Norway
}

Correspondence: Christian Beisland Department of Urology, Haukeland University Hospital, PO Box I400,

$\mathrm{N}$-502I Bergen, Norway

Tel +4755972902

Fax +4755 972757

Email christian.beisland@helse-bergen.no
This article was published in the following Dove Press journal:

OncoTargets and Therapy

16 January 2017

Number of times this article has been viewed

Background: This population-wide retrospective, non-interventional registry study assessed changes in overall survival (OS) and factors influencing OS in Norwegian patients with renal cell carcinoma (RCC).

Methods: Two population-wide health registries were used to identify all RCC patients with (mRCC) or without metastases diagnosed before (2002-2005) and after (2006-2008 and 2009-2011) introduction of targeted therapies. Median OS was estimated using Kaplan-Meier method. Cox proportional hazards regression modeling was used to identify prognostic factors. Results: Overall, 5,463 patients were diagnosed with RCC during 2002-2005 ( $\mathrm{n}=1,898)$, 2006-2008 ( $\mathrm{n}=1,631)$, and 2009-2011 ( $\mathrm{n}=1,934)$; of these, 1,678 (31\%) had mRCC. Patients diagnosed in 2009-2011 and 2006-2008 had significant $(P<0.001)$ improvements in OS versus those diagnosed in 2002-2005: median OS, not reached and not reached versus 82.0 months in RCC; 14.0 and 12.0 months versus 9.0 months in mRCC. Similarly, OS improvements were seen in the primary and elderly ( $\geq 75$ years) mRCC populations. Median OS was comparable (12 months) between clear cell and papillary mRCC, but it was longer (24.0 months) for chromophobe mRCC. Multivariate regression analyses showed that younger age, previous nephrectomy, and 1 or more prescriptions of targeted therapy were significantly associated with longer OS in $\mathrm{mRCC}$ patients.

Conclusion: OS increased in RCC and mRCC patients in Norway between 2002 and 2011 following introduction of targeted therapies.

Keywords: nephrectomy, Norway, overall survival, renal cell carcinoma, targeted therapy

\section{Introduction}

Better understanding of the biological processes underlying renal cell carcinoma (RCC) has allowed the development and approval of targeted therapies for first-, second-, or subsequent-line therapy for metastatic RCC (mRCC) since 2005..$^{1-3}$ These therapies include the tyrosine kinase inhibitors (TKIs) sorafenib, sunitinib, pazopanib, and axitinib; ${ }^{4-7}$ the anti-vascular endothelial growth factor (VEGF) monoclonal antibody bevacizumab; ${ }^{8,9}$ and the mammalian target of rapamycin inhibitors temsirolimus and everolimus. $^{10,11}$

RCCs may be classified according to the pattern of genetic mutations, morphology, growth pattern, histology, and underlying molecular mechanisms. ${ }^{12}$ The majority of RCCs (75\%-80\%) are classified histologically as clear cell, and non-clear cell subtypes include papillary RCC and chromophobe RCC, which account for $10 \%-15 \%$ and 5\% of RCCs, respectively. ${ }^{13}$ Clear cell RCC has a strong association with alterations in the von Hippel-Lindau gene ${ }^{14}$ and resultant deregulation of hypoxia-inducible 
factor signaling and downstream targets such as VEGF. ${ }^{15}$ Thus, clinical trials of targeted therapies primarily focus on clear cell RCC.

A series of randomized clinical trials (RCTs) have shown that molecular targeting of the VEGF receptor pathway improves outcomes in patients with $\mathrm{mRCC}$, in terms of both progression-free survival (PFS) and overall survival (OS), compared with placebo or cytokine therapy. However, due to the often strict inclusion criteria of RCTs, the survival benefit observed in these studies may not necessarily reflect the situation in the general $\mathrm{mRCC}$ population, where patients are more heterogeneous and likely to be less healthy and elderly. ${ }^{16,17}$ In addition, differences in adaptation and clinical practice when introducing new therapies cannot be ascertained from RCTs, whereas data derived from national population-based registries have the potential to provide useful real-world insights into both of these issues. Although an increasing body of information supports that targeted therapy improves OS in real-world practice, ${ }^{18-20}$ few studies have explored this on a national level. Comprehensive national cancer and drug prescription registries in the Nordic countries cover the whole population and, hence, provide a unique opportunity for studying the prognostic impact of new cancer medications within a real-life population and form the basis of robust real-world epidemiologic research..$^{21,22}$

Norway has a national public health service that aims to provide equal care to all patients. Drugs, including those for cancer treatment, are clinically approved based on the central procedure of the European Medicines Agency (EMA), followed by a centralized reimbursement application process for each drug. However, cancer survival rates vary by region in Norway, partly due to differences in implementation of new therapies. ${ }^{23}$ With the aim of counteracting these differences and improving quality of cancer care, since May 1, 2015, the Norwegian Directorate of Health has set defined timelines and therapy milestones termed "National Cancer Pathways" for several cancer types, including RCC.

The Renal Comparison study in Norway (RECON) is a retrospective, non-interventional study utilizing data from 2 national health registries. The primary objective of RECON was to estimate survival over time and to investigate factors influencing survival in the Norwegian RCC and mRCC populations. The effect of targeted therapies on OS was assessed by comparing data from patients diagnosed during 1 period before (2002-2005) and 2 periods after (2006-2008 and 2009-2011) the introduction of targeted therapies to reflect the arrival of new therapy options and increased experience in using available therapies.

\section{Methods}

\section{Study design and patients}

This was a retrospective study using data from 2 national public health registries in Norway, covering the entire country's population; the Cancer Registry of Norway (CRN) and the Norwegian Prescription Database (NorPD). The CRN includes diagnosis and death records from 1952 onward and is continuously updated and matched to information from the Cause of Death Registry at Statistics Norway and the National Registry on vital statistics and migration. Data within the $\mathrm{CRN}$ are accurate, close-to-complete, and timely. ${ }^{24}$ The NorPD was established in 2004 and documents all drugs dispensed at pharmacies in Norway. ${ }^{25}$ The database is considered valid and reliable. ${ }^{26}$

The primary database for this study was CRN data collected from 2002 to 2011, including additional hospital administrative data available at $\mathrm{CRN}$, merged with data from NorPD. The study included all patients aged $\geq 16$ years from all 19 Norwegian counties diagnosed between January 1, 1995, and December 31, 2011, with a histologically confirmed RCC of any stage, including patients with metastases. From the total RCC population, those with mRCC were derived and included in the $\mathrm{mRCC}$ patient group in the following way: when 1 of 3 event criteria was recorded in the registry, whichever occurred first: 1) registration in $\mathrm{CRN}$ of primary metastasis (M1 disease) at the first date of RCC or within 3 months thereafter; 2) a later clinical or pathology report in CRN confirming metastases for the patient; and 3 ) the first date of prescription of any targeted therapy medication for an RCC patient registered in the NorPD. All mRCC patients were further classified into histological subtypes of clear cell, papillary, or chromophobe, according to the International Classification of Diseases (ICD)-O-3 coding in CRN. Other histological subtypes still diagnosed and registered as C64.9 were pooled and presented as "other". For comparator purpose, the following 3 cohorts were defined: RCC or mRCC patients diagnosed between 2002-2005, 2006-2008, and 2009-2011. Targeted therapy was defined as any medication dispensed after diagnosis of mRCC with the Anatomical Therapeutic Classification (ATC) code L01XE04 (sunitinib), L01XE05 (sorafenib), L01XE10 (everolimus), L01XE11 (pazopanib), or L01XE17 (axitinib). The primary end point of the study was OS measured as time to death from the date of diagnosis of RCC or mRCC. Patients were 
followed up until death, emigration, or end of follow-up (June 15, 2013).

Both CRN and NorPD are central national Norwegian registries with an estimated coverage of $99 \%$ of population containing validated data of documented high quality. ${ }^{24}$ Data from CRN and NorPD were linked using the national identification number that was encrypted and made unidentifiable according to standard procedures. Institutional review board approval and informed written consent from included study patients were not needed because the use of national registry data for scientific purposes is regulated by the Personal Health Data Filing System Act when unidentifiable data are used. ${ }^{27}$

\section{Statistical methods}

All data were presented using descriptive statistics, ie, frequency and relative frequency for categorical variables and mean and standard deviation (SD) for continuous variables. Median OS was estimated by the Kaplan-Meier method and compared between patients diagnosed in 2002-2005 versus 2006-2008 or 2009-2011, using the log-rank test. In addition to median OS, the first and third quartile survival (ie, time point for $75 \%$ and $25 \%$ cumulative survival of patients, respectively) was calculated. Multivariate regression analysis was performed using a Cox proportional hazards model. The regression models included the following covariates: period of diagnosis, age, gender, nephrectomy status, and regional variation (ie, different county); additionally, for $\mathrm{mRCC}$ patients, the prescription dispensed for at least 1 targeted therapy versus no targeted therapy, as well as lines of therapy. Subgroup analysis was also performed on the primary, elderly (aged $\geq 75$ years), and clear cell $\mathrm{mRCC}$ populations. All tests were 2-sided, and $P<0.05$ was regarded as statistically significant. IBM SPSS Statistics version 22 (IBM Corporation, Armonk, NY, USA) was used for statistical analysis.

\section{Results \\ Patients}

Between January 2002 and December 2011, a total of 5,463 patients aged $\geq 16$ years were diagnosed with $R C C$ of a known or confirmed histology: 1,898 patients in 2002-2005, 1,631 in 2006-2008, and 1,934 in 2009-2011 (Table 1). Of all RCC patients, 1,678 (31\%) met the criteria for mRCC diagnosis, most of whom $(62 \%)$ had primary metastasis (ie, diagnosed within 90 days of RCC diagnosis). For the purpose of analyses reported here, 60 patients included in the 2009-2011 period were diagnosed with RCC in 2011, but met the diagnosis for mRCC in 2012 or 2013. In all, 2,321 (42.5\%) of 5,463 RCC patients and 1,373 (81.8\%) of $1,678 \mathrm{mRCC}$ patients had died.

In the RCC and mRCC population, respectively, mean $\pm \mathrm{SD}$ (median, range) age at diagnosis was $65.0 \pm 12.5$ $(66,17-94)$ and $65.5 \pm 11.6(66,19-92)$ years, $3,552(65.0 \%)$ and $1,150(68.5 \%)$ were male, and 4,539 (83.1\%) and 1,091 $(65.0 \%)$ had undergone prior nephrectomy (Table 1). The percentage of patients who did not receive prior nephrectomy remained relatively constant among the 3 cohorts: $\sim 17 \%$ and $\sim 35 \%$ in the RCC and $\mathrm{mRCC}$ populations, respectively. According to the primary histological classification registered in the CRN of all the mRCC patients, 1,453 (86.6\%) had a clear cell RCC, 94 (5.6\%) had papillary RCC, 16 (1.0\%) had chromophobe RCC, and 115 (6.9\%) were classified as "other". Baseline patient and disease characteristics for patients diagnosed with RCC or mRCC in the 2006-2008 and 2009-2011 cohorts were comparable to that for patients in the 2002-2005 cohort (Table 1).

\section{Targeted therapy in $\mathrm{mRCC}$ patients}

Among 1,678 patients diagnosed with mRCC, 698 (41.6\%) were dispensed at least 1 targeted therapy using TKIs; of those dispensed such therapy, 523 (31.2\%) had also undergone prior nephrectomy (Table 1). The percentage of mRCC patients who received both prior nephrectomy and targeted therapy increased from $10.5 \%$ to $45.7 \%$ over the study period. First-line targeted therapy was used in $5.0 \%(\mathrm{n}=27)$ of 542 mRCC patients diagnosed in 2002-2005 compared with $41.5 \%(n=210)$ of 506 and $62.1 \%(n=391)$ of $630 \mathrm{mRCC}$ patients diagnosed in 2006-2008 and 2009-2011, respectively (Table 2). Regardless of line of therapy, use of targeted therapies increased from $22.6 \%$ to $70.7 \%$ between 2006 and 2011. In 2011, mean age (SD) of the mRCC patients who received targeted therapy was $62.0(12.2)$ years, compared with 70.9 (11.3) years for those who were not treated with targeted therapy.

The most common targeted therapy to be given as firstline therapy was sunitinib, which for the period 2002-2011 was used in 575 of $628(91.6 \%)$ patients who received firstline targeted therapy. The proportion of patients who did not receive any systemic therapy decreased steadily from $94.2 \%$ in 2002 to $27.6 \%$ in 2011 . The proportion of patients receiving cytokines as first-line therapy increased from $2.9 \%$ in 2002 to $18 \%$ during the 2004-2006 period, followed by a sharp decline to $1 \%$ in 2007 and beyond. Over the study period, an increasing proportion of $\mathrm{mRCC}$ patients received 
Table I Patient baseline and disease characteristics

\begin{tabular}{|c|c|c|c|c|c|c|c|c|}
\hline \multirow[t]{3}{*}{ Variable } & \multicolumn{4}{|l|}{ RCC } & \multicolumn{4}{|l|}{ mRCC } \\
\hline & Total & 2002-2005 & 2006-2008 & 2009-20II & Total & 2002-2005 & 2006-2008 & 2009-2011 \\
\hline & $(n=5,463)$ & $(n=I, 898)$ & $(n=I, 63 I)$ & $(n=1,934)$ & $(n=1,678)$ & $(n=542)$ & $(n=506)$ & $(n=630)$ \\
\hline \multicolumn{9}{|l|}{ Year of diagnosis, $\mathrm{n}(\%)$} \\
\hline $2002-2005$ & $\mathrm{I}, 898(34.7)$ & - & - & - & $542(32.3)$ & - & - & - \\
\hline $2006-2008$ & I,63I (29.9) & - & - & - & $506(30.2)$ & - & - & - \\
\hline $2009-2011$ & I,934 (35.4) & - & - & - & $630(37.5)$ & - & - & - \\
\hline Age at diagnosis, mean (SD), years & $65.0(12.5)$ & $65.4(12.7)$ & $65.2(12.4)$ & $64.4(12.3)$ & $65.5(11.6)$ & $65.2(11.7)$ & $66.1(11.2)$ & $65.3(11.9)$ \\
\hline \multicolumn{9}{|l|}{ Gender, n (\%) } \\
\hline Male & $3,552(65.0)$ & $\mathrm{I}, 218(64.2)$ & $\mathrm{I}, 036(63.5)$ & I,298 (67.I) & $\mathrm{I}, \mathrm{I} 50(68.5)$ & $363(67.0)$ & $358(70.8)$ & $429(68.1)$ \\
\hline Female & I,9II (35.0) & $680(35.8)$ & $595(36.5)$ & $636(32.9)$ & $528(31.5)$ & $179(33.0)$ & I 48 (29.2) & $20 I(3 I .9)$ \\
\hline \multicolumn{9}{|l|}{ RCC histology, n (\%) } \\
\hline Clear cell & $4,359(79.8)$ & I,567 (82.6) & I,3।8 (80.8) & $\mathrm{I}, 474(76.2)$ & I,453 (86.6) & $467(86.2)$ & $44 I(87.2)$ & $545(86.5)$ \\
\hline Papillary & $705(12.9)$ & $198(10.4)$ & $191(11.7)$ & $316(16.3)$ & $94(5.6)$ & $26(4.8)$ & $29(5.7)$ & $39(6.2)$ \\
\hline Chromophobe & $190(3.5)$ & $46(2.4)$ & $57(3.5)$ & $87(4.5)$ & $16(1.0)$ & $4(0.7)$ & $4(0.8)$ & $8(1.3)$ \\
\hline Other & $209(3.8)$ & $87(4.6)$ & $65(4.0)$ & $57(2.9)$ & $115(6.9)$ & $45(8.3)$ & $32(6.3)$ & $38(6.0)$ \\
\hline \multicolumn{9}{|l|}{ Metastasis, n (\%) } \\
\hline No & $3,930(71.9)$ & I,329 (70.0) & I,I5I (70.6) & $\mathrm{I}, 450(75.0)$ & 0 & 0 & 0 & 0 \\
\hline Yes & I,533 (28.I) & $569(30.0)$ & $480(29.4)$ & $484(25.0)$ & $\mathrm{I}, 678(100)$ & $542(100)$ & $506(100)$ & $630(100)$ \\
\hline \multicolumn{9}{|l|}{ Prior nephrectomy, n (\%) } \\
\hline No & $924(16.9)$ & $332(17.5)$ & $263(16.1)$ & $329(17.0)$ & $587(35.0)$ & $192(35.4)$ & $178(35.2)$ & $217(34.4)$ \\
\hline Yes & $4,539(83.1)$ & $1,566(82.5)$ & I,368 (83.9) & I,605 (83.0) & $|, 09|(65.0)$ & $350(64.6)$ & $328(64.8)$ & $413(65.6)$ \\
\hline \multicolumn{9}{|l|}{ Death, n (\%) } \\
\hline No & $3,142(57.5)$ & $816(43.0)$ & 941 (57.7) & I,385 (7I.6) & $305(I 8.2)$ & $34(6.3)$ & 59 (11.7) & $212(33.7)$ \\
\hline Yes & $2,321(42.5)$ & $\mathrm{I}, 082(57.0)$ & $690(42.3)$ & $549(28.4)$ & I,373 (8I.8) & $508(93.7)$ & $447(88.3)$ & $418(66.3)$ \\
\hline \multicolumn{9}{|l|}{ TKI used, n (\%) } \\
\hline No & - & - & - & - & $980(58.4)$ & $48 \mid$ (88.7) & $268(53.0)$ & 231 (36.7) \\
\hline Yes & - & - & - & - & $698(41.6)$ & $61(11.3)$ & $238(47.0)$ & $399(63.3)$ \\
\hline \multicolumn{9}{|c|}{ Combination of TKI and prior nephrectomy, n (\%) } \\
\hline TKI-no/nephrectomy-yes & - & - & - & - & $568(33.8)$ & $293(54.1)$ & $150(29.6)$ & $125(19.8)$ \\
\hline TKI-yes/nephrectomy-no & - & - & - & - & $175(10.4)$ & $4(0.7)$ & $60(11.9)$ & III (I7.6) \\
\hline TKI-no/nephrectomy-no & - & - & - & - & $412(24.6)$ & $188(34.7)$ & $118(23.3)$ & $106(16.8)$ \\
\hline TKI-yes/nephrectomy-yes & - & - & - & - & $523(31.2)$ & $57(10.5)$ & $178(35.2)$ & $288(45.7)$ \\
\hline
\end{tabular}

Abbreviations: mRCC, metastatic renal cell carcinoma; RCC, renal cell carcinoma; SD, standard deviation; TKI, tyrosine kinase inhibitor.

additional lines of therapy (Table 2). The percentage of patients diagnosed in 2004 who received first-line therapy and went on to receive second-line therapy was $25 \%$, whereas the corresponding share was $45 \%$ in 2011.

\section{OS in RCC, mRCC, primary $\mathrm{mRCC}$, and elderly $\mathrm{mRCC}$ populations}

Among all RCC patients diagnosed between 2002 and 2011, unadjusted median OS (95\% confidence interval [95\% CI]) was 92.0 months (85.9-98.2). There was a clear trend for incrementally improved OS in RCC patients diagnosed between 2002 and 2011 (Figure 1A). Significant $(P<0.001)$ improvements in OS were observed in RCC patients diagnosed in the later years 2009-2011 and 2006-2008 (median: not reached for both) compared with those diagnosed in 2002-2005 (median 82.0 months; 95\% CI: 73.9-90.0) (Figure 1B).

Among all mRCC patients diagnosed between 2002 and 2011, unadjusted median OS (95\% CI) was 11.0 months
(9.8-12.2). A noticeable trend of incrementally improved OS was also observed between 2002 and 2011 in this population (Figure 2A). Median OS for mRCC patients diagnosed in 2009-2011 and 2006-2008 (14.0 and 12.0 months, respectively) was significantly longer than 9.0 months for patients diagnosed in 2002-2005 (both $P<0.001$; Figure $2 \mathrm{~B})$. When analyzed per quartile, the first quartile survival (75\% cumulative survival) in 2009-2011, 2006-2008, and 2002-2005, respectively, was 4.0, 4.0, and 3.0 months and the corresponding third quartile survival $(25 \%$ cumulative survival) was 43.0, 35.0, and 25.0 months. The interquartile range was 39.0 and 31.0 months for the 2009-2011 and 2006-2008 cohorts, respectively, compared with 22.0 months for the 2002-2005 cohort (Figure 2B).

Among mRCC patients diagnosed between 2002 and 2011 who had primary mRCC $(n=1,048)$, unadjusted overall median OS $(95 \% \mathrm{CI})$ was 9.0 months (7.9-10.1) (Figure S1A). In the 2002-2005 and 2006-2008 cohorts, 
Table 2 Distribution of subjects with first-line therapy and lines of therapy prescribed by year of mRCC diagnosis in Norwegian patients with $\mathrm{mRCC}$

\begin{tabular}{|c|c|c|c|c|c|c|c|c|c|c|}
\hline \multirow[t]{2}{*}{ Therapy } & 2002 & 2003 & 2004 & 2005 & 2006 & 2007 & 2008 & 2009 & 2010 & 2011 \\
\hline & $(n=139)$ & $(n=\mid 18)$ & $(n=149)$ & $(n=136)$ & $(n=155)$ & $(n=175)$ & $(n=176)$ & $(n=178)$ & $(n=227)$ & $(n=225)$ \\
\hline First-line therapy, n (\%) & $8(5.8)$ & $9(7.6)$ & $44(29.5)$ & $37(27.2)$ & $65(41.9)$ & $90(5 \mathrm{I} .4)$ & $90(5 \mathrm{I} .1)$ & $95(53.4)$ & |4| (62.I) & $163(72.4)$ \\
\hline Chemotherapy, n (\%) & I (0.7) & 0 & $7(4.7)$ & 0 & $3(1.9)$ & I (0.6) & I (0.6) & 0 & $2(0.9)$ & $2(0.9)$ \\
\hline Hydroxyurea, n & I & 0 & 7 & 0 & 3 & I & I & 0 & 2 & 2 \\
\hline Cytokine therapy, n (\%) & $4(2.9)$ & $7(5.9)$ & $27(18.1)$ & $25(18.4)$ & $27(17.4)$ & $2(1.1)$ & I (0.6) & I (0.6) & I (0.4) & $2(0.9)$ \\
\hline Interferon- $\alpha-2 a, n$ & 3 & 5 & 15 & 18 & 22 & 0 & I & I & I & 2 \\
\hline Interferon- $\alpha-2 b, \mathrm{n}$ & I & 2 & 12 & 7 & 5 & 2 & 0 & 0 & 0 & 0 \\
\hline Targeted therapy, n (\%) & $3(2.2)$ & $2(1.7)$ & $10(6.7)$ & $12(8.8)$ & $35(22.6)$ & $87(49.7)$ & $88(50.0)$ & $94(52.8)$ & 138 (60.8) & $159(70.7)$ \\
\hline Sunitinib, n & 3 & 2 & 8 & 9 & 29 & 78 & 85 & 93 & 130 & 138 \\
\hline Sorafenib, $n$ & 0 & 0 & 2 & 3 & 6 & 7 & 0 & I & 1 & 0 \\
\hline Pazopanib, n & 0 & 0 & 0 & 0 & 0 & 2 & I & 0 & 3 & 18 \\
\hline Everolimus, $\mathrm{n}$ & 0 & 0 & 0 & 0 & 0 & 0 & I & 0 & 4 & 3 \\
\hline Axitinib, $\mathrm{n}$ & 0 & 0 & 0 & 0 & 0 & 0 & I & 0 & 0 & 0 \\
\hline No therapy, n (\%) & |3| (94.2) & $109(92.4)$ & $105(70.5)$ & $99(72.8)$ & $90(58.1)$ & $85(48.6)$ & $86(48.9)$ & $83(46.6)$ & $86(37.9)$ & $62(27.6)$ \\
\hline \multicolumn{11}{|l|}{ Line of therapy, ${ }^{\mathrm{a}} \mathrm{n}(\%)$} \\
\hline First line & $8(100)$ & $9(100)$ & $44(100)$ & $37(100)$ & $65(100)$ & $90(100)$ & $90(100)$ & $95(100)$ & I4I (100) & $163(100)$ \\
\hline Second line & I (I3) & I (II) & I I (25) & $23(62)$ & $30(46)$ & $28(31)$ & $40(44)$ & $48(5 I)$ & $70(50)$ & $73(45)$ \\
\hline Third line & 0 & 0 & $7(16)$ & $9(24)$ & $12(18)$ & $10(\mathrm{II})$ & $22(24)$ & $28(29)$ & $34(24)$ & $26(16)$ \\
\hline Fourth line & 0 & 0 & $2(5)$ & $5(14)$ & $4(6)$ & $2(2)$ & $8(9)$ & $16(17)$ & $17(12)$ & $10(6)$ \\
\hline Fifth line & 0 & 0 & 0 & $3(8)$ & I (2) & 0 & $4(4)$ & $6(6)$ & $8(6)$ & $5(3)$ \\
\hline Sixth line & 0 & 0 & 0 & $2(5)$ & I (2) & 0 & $2(2)$ & $3(3)$ & $4(3)$ & $3(2)$ \\
\hline Seventh line & 0 & 0 & 0 & I (3) & 0 & 0 & I (I) & $3(3)$ & $2(1)$ & $2(I)$ \\
\hline Eighth line & 0 & 0 & 0 & 0 & 0 & 0 & I (I) & $2(2)^{b}$ & 0 & 0 \\
\hline
\end{tabular}

Notes: aPercentage calculated as the proportion of patients who received first-line therapy. ${ }^{\mathrm{b}}$ One patient received I I th-line therapy.

Abbreviation: mRCC, metastatic renal cell carcinoma.

median OS (95\% CI) was $8.0(6.6-9.4)$ and 8.0 months (5.7-10.4), respectively, which increased to 10.0 months (7.6-12.3) in the 2009-2011 cohort (Figure S1B). In the elderly subgroup of mRCC patients diagnosed between 2002 and $2011(n=403)$, unadjusted overall median OS

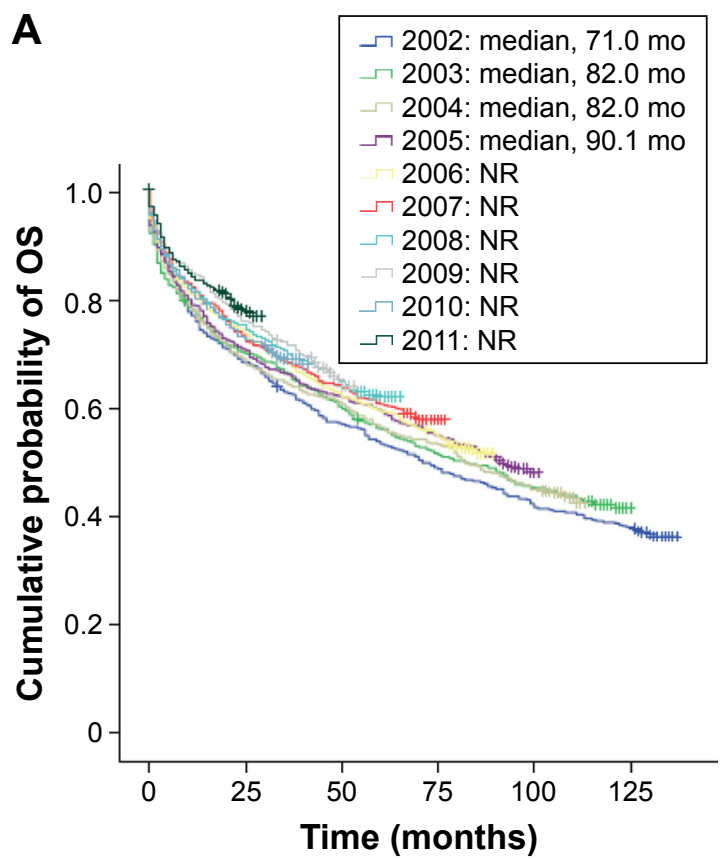

(95\% CI) was 5.9 months (4.6-7.3) (Figure S2A). In this same subgroup, median OS $(95 \% \mathrm{CI})$ increased steadily from 3.0 months (2.5-3.6) in the 2002-2005 cohort to 6.0 months (4.8-7.2) in the 2006-2008 cohort and to 8.0 months (4.9-11.1) in the 2009-2011 cohort (Figure S2B).

B

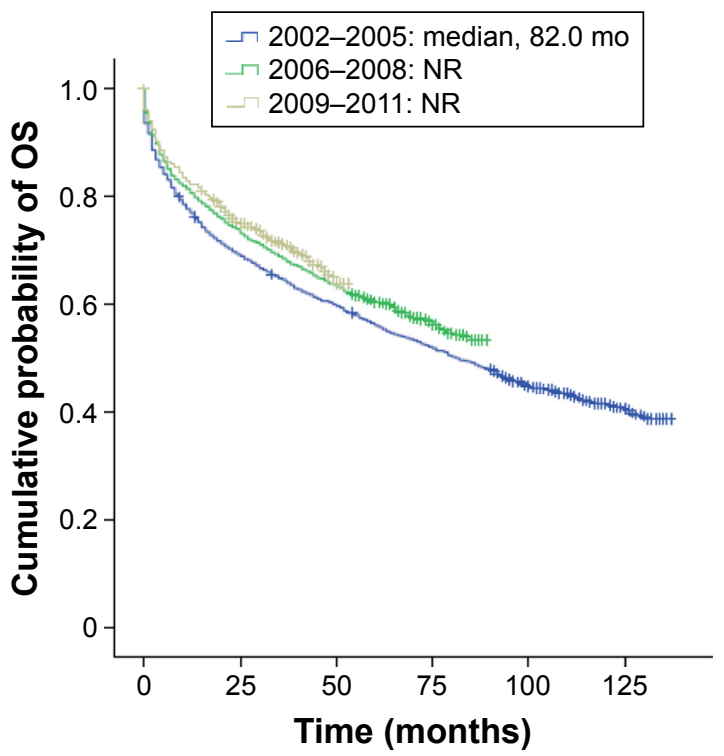

Figure I Kaplan-Meier estimates of OS in Norwegian patients diagnosed with RCC: (A) by year of diagnosis and (B) by cohorts 2002-2005, 2006-2008, and 2009-20I I. Abbreviations: mo, months; NR, not reached; OS, overall survival; RCC, renal cell carcinoma. 
A

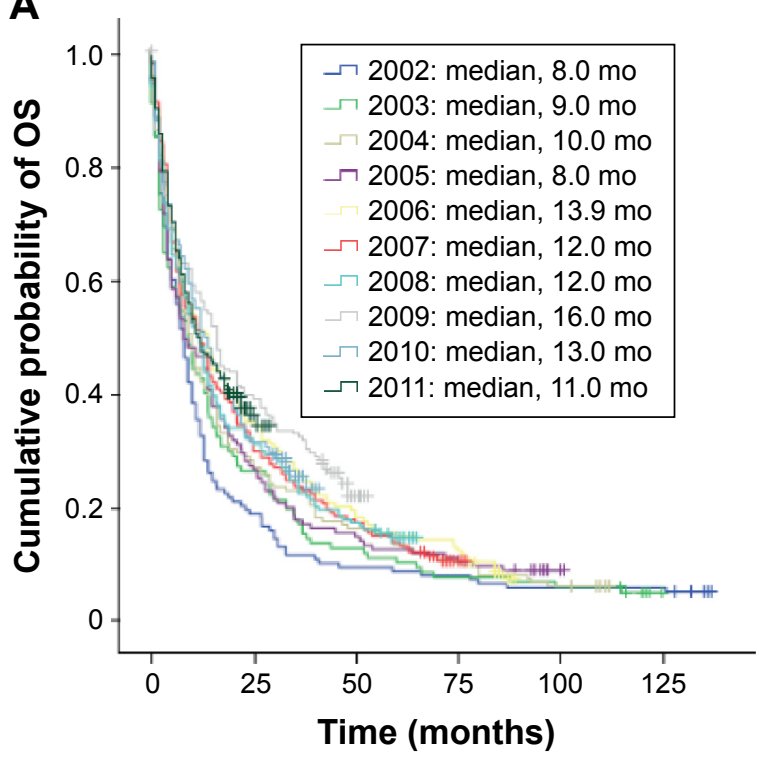

B

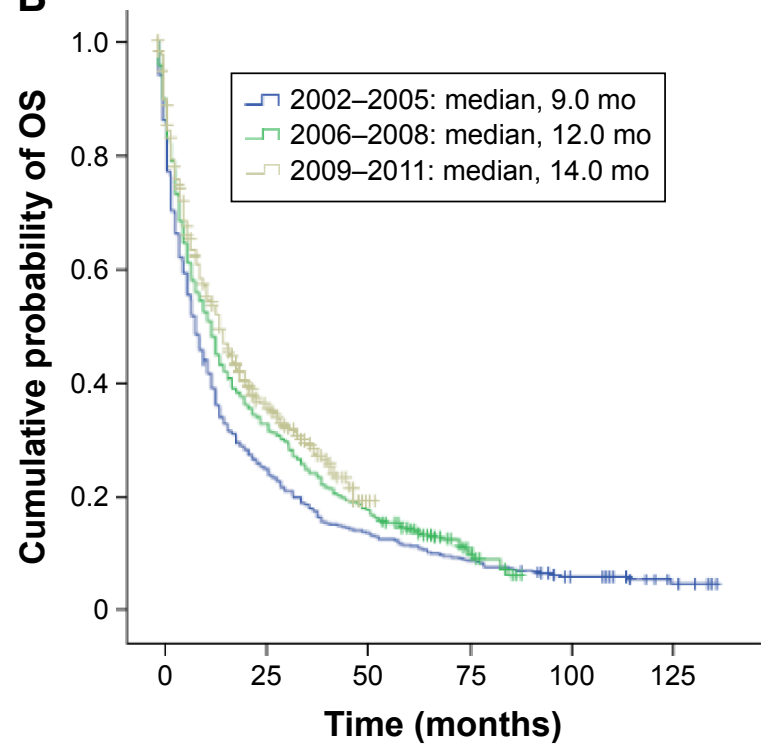

Figure 2 Kaplan-Meier estimates of OS in Norwegian patients diagnosed with mRCC: (A) by year of diagnosis and (B) by cohorts 2002-2005, 2006-2008, and 2009-20II. Abbreviations: mo, months; $\mathrm{mRCC}$, metastatic renal cell carcinoma; OS, overall survival.

\section{OS by histological subgroups}

Median OS (95\% CI) in mRCC patients with disease of clear cell and papillary histology was $12.0(11.0-13.0)$ and 12.0 months (6.5-17.5), respectively. Patients with chromophobe mRCC had the longest median OS of 24.0 months (95\% CI: 10.4-37.7). Patients with tumors classified as "other" had a median OS of 4.0 months $(95 \%$ CI: 3.5-4.5) (Figure 3).

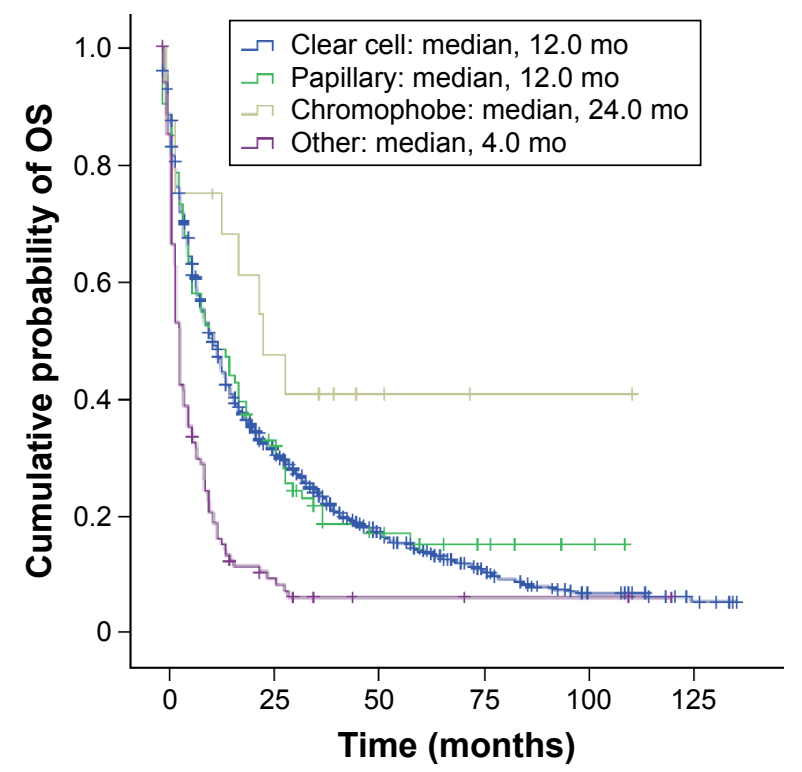

Figure 3 Kaplan-Meier estimates of OS in Norwegian patients diagnosed with mRCC of different histology.

Abbreviations: mo, months; $\mathrm{mRCC}$, metastatic renal cell carcinoma; OS, overall survival.

\section{OS according to predictive factors}

In the RCC population, multivariate regression analyses showed that compared with patients diagnosed in 2002-2005, patients diagnosed in 2009-2011 and 2006-2008 had a significant reduction in the risk of death: hazard ratio (HR) 0.767 (95\% CI: 0.687-0.856; $P<0.001)$ and 0.880 (95\% CI: 0.797-0.972; $P=0.011$ ), respectively (Table 3). Other factors associated with significantly improved OS in the RCC population were female gender, younger age, and prior nephrectomy.

In the mRCC population, whether overall or primary, elderly, or clear cell subgroups, multivariate analysis did not show any significant reduction in the risk of death in patients diagnosed in 2009-2011 or 2006-2008 relative to 2002-2005 (Table 3). However, overall, mRCC patients who received at least 1 targeted therapy had a significantly reduced risk of death versus those who did not receive targeted therapy (HR 0.573; 95\% CI: $0.505-0.651 ; P<0.001$; Table 3), with median adjusted OS of 17.0 and 8.0 months, respectively (Figure 4A). Patients who received additional lines of any therapy had a significantly reduced risk of death compared with no therapy: 1 line only (HR 0.713 ; 95\% CI: $0.621-0.818 ; P<0.001$ ); 2 lines (HR 0.574; 95\% CI: $0.472-$ 0.699; $P<0.001$ ); and 3 or more lines (HR $0.369 ; 95 \%$ CI: 0.292-0.466; $P<0.001$ ) (Table S1). Two or more lines of therapy were associated with longer OS: median OS for mRCC patients who received 1, 2, and 3 or more lines of therapy was 13,17 , and 33 months, respectively, compared 
Table 3 Multivariate Cox proportional hazards regression analysis for factors predictive for OS in RCC, mRCC, and subgroups of mRCC patients in Norway diagnosed between 2002 and 2011

\begin{tabular}{|c|c|c|c|c|c|c|}
\hline \multirow[t]{2}{*}{ Variable } & \multicolumn{3}{|c|}{$\operatorname{RCC}(\mathbf{N}=5,463)$} & \multicolumn{3}{|c|}{$\operatorname{mRCC}(n=I, 678)$} \\
\hline & \multicolumn{2}{|l|}{$\operatorname{HR}(95 \% \mathrm{CI})^{a}$} & $P$-value & \multicolumn{2}{|c|}{$\operatorname{HR}(95 \% \mathrm{CI})^{\mathrm{b}}$} & $P$-value \\
\hline \multicolumn{7}{|l|}{ Year of diagnosis } \\
\hline 2002-2005 & \multicolumn{2}{|l|}{1.000} & - & \multicolumn{2}{|l|}{1.000} & - \\
\hline 2006-2008 & \multicolumn{2}{|c|}{$0.880(0.797-0.972)$} & 0.011 & \multicolumn{2}{|c|}{$1.006(0.877-1.153)$} & 0.935 \\
\hline 2009-20II & \multicolumn{2}{|c|}{$0.767(0.687-0.856)$} & $<0.001$ & \multicolumn{2}{|c|}{0.911 (0.788-1.054) } & 0.209 \\
\hline \multicolumn{7}{|l|}{ Gender ${ }^{c}$} \\
\hline Female vs male & \multicolumn{2}{|c|}{$0.790(0.723-0.864)$} & $<0.001$ & \multicolumn{2}{|c|}{$0.894(0.795-1.004)$} & 0.059 \\
\hline \multicolumn{7}{|l|}{ Age, years } \\
\hline$\leq 49$ & \multicolumn{2}{|l|}{1.000} & - & \multicolumn{2}{|c|}{1.000} & - \\
\hline $50-59$ & \multicolumn{2}{|c|}{$1.419(1.162-1.732)$} & $<0.001$ & \multicolumn{2}{|c|}{$0.975(0.778-1.222)$} & 0.824 \\
\hline $60-69$ & \multicolumn{2}{|c|}{$1.916(1.591-2.306)$} & $<0.001$ & \multicolumn{2}{|c|}{$1.229(0.993-1.522)$} & 0.058 \\
\hline $70-79$ & \multicolumn{2}{|c|}{$2.467(2.056-2.960)$} & $<0.001$ & \multicolumn{2}{|c|}{$1.287(1.036-1.600)$} & 0.023 \\
\hline$\geq 80$ & \multicolumn{2}{|c|}{$2.765(2.272-3.365)$} & $<0.001$ & \multicolumn{2}{|c|}{$1.379(1.068-1.78 \mid)$} & 0.014 \\
\hline \multicolumn{7}{|l|}{ Prior nephrectomy ${ }^{c}$} \\
\hline Yes vs no & $0.121(0.109-0$. & & $<0.001$ & 0.463 & +||$-0.52 I)$ & $<0.001$ \\
\hline$\geq \mathrm{I}$ targeted therapy pres & tion dispensed ${ }^{c}$ & & & & & \\
\hline Yes vs no & - & & - & 0.573 & $05-0.65 \mathrm{I})$ & $<0.001$ \\
\hline Subgroup $\mathrm{mRCC}$ patie & & & & & & \\
\hline Variable & Primary $m R C C(n=$ & 048) & mRCC age $75+(n=$ & & Clear cell mRCC & ,453) \\
\hline & HR $(95 \% \mathrm{CI})^{\mathrm{b}}$ & $P$-value & $\operatorname{HR}(95 \% \mathrm{CI})^{\mathrm{b}}$ & $P$-value & HR $(95 \% \mathrm{CI})^{\mathrm{b}}$ & $P$-value \\
\hline Year of diagnosis & & & & & & \\
\hline $2002-2005$ & 1.000 & - & 1.000 & - & 1.000 & - \\
\hline 2006-2008 & I.I38 (0.962-I.347) & 0.132 & $0.904(0.695-1.176)$ & 0.453 & 1.031 (0.888-I.196) & 0.690 \\
\hline $2009-2011$ & $1.080(0.900-1.296)$ & 0.407 & $0.829(0.622-1.104)$ & 0.200 & $0.918(0.784-1.073)$ & 0.283 \\
\hline Gender ${ }^{c}$ & & & & & & \\
\hline Female vs male & $0.910(0.786-1.054)$ & 0.210 & $0.936(0.746-1.173)$ & 0.564 & $0.919(0.811-1.042)$ & 0.187 \\
\hline Age, years & & & & & & \\
\hline$\leq 49$ & 1.000 & - & - & - & 1.000 & - \\
\hline $50-59$ & $0.983(0.74 \mid-1.305)$ & 0.908 & - & - & $0.921(0.719-1.178)$ & 0.510 \\
\hline $60-69$ & $1.049(0.806-1.366)$ & 0.721 & - & - & $1.194(0.944-1.510)$ & 0.138 \\
\hline 70-79 & $1.010(0.77 \mid-1.322)$ & 0.944 & - & - & $1.27 \mid(1.001-1.613)$ & 0.049 \\
\hline$\geq 80$ & $1.032(0.756-1.408)$ & 0.843 & - & - & $1.328(1.000-1.762)$ & 0.050 \\
\hline Targeted therapy combin & ith nephrectomy & & & & & \\
\hline Neither therapy & 1.000 & - & - & - & - & - \\
\hline Nephrectomy only & $0.350(0.29 I-0.42 I)$ & $<0.001$ & $0.514(0.406-0.65 \mathrm{I})^{\mathrm{d}}$ & $<0.001$ & $0.460(0.405-0.524)^{\mathrm{d}}$ & $<0.00 \mathrm{I}$ \\
\hline Targeted therapy only & $0.402(0.322-0.502)$ & $<0.001$ & $0.470(0.347-0.636)^{\mathrm{e}}$ & $<0.001$ & $0.554(0.483-0.635)^{\mathrm{e}}$ & $<0.00 \mathrm{I}$ \\
\hline Both therapies & $0.235(0.189-0.292)$ & $<0.001$ & - & - & - & - \\
\hline
\end{tabular}

Notes: adjusted for geographic region and histology. ${ }^{\mathrm{b}}$ Adjusted for geographic region. 'For binary variables, an HR $<\mathrm{I}$ equates to risk reduction for the first category and an $\mathrm{HR}>\mathrm{I}$ equates to risk reduction for the second category. ${ }^{\mathrm{N}}$ Nephrectomy yes vs no. ${ }^{\mathrm{e}}$ Targeted therapy yes vs no.

Abbreviations: $\mathrm{Cl}$, confidence interval; $\mathrm{HR}$, hazard ratio; $\mathrm{mRCC}$, metastatic renal cell carcinoma; OS, overall survival; RCC, renal cell carcinoma.

with 8 months for those who did not receive any therapy (Figure S3). Younger age and prior nephrectomy were also associated with significantly improved OS in mRCC patients, whereas gender was not (Table 3 ).

In the subgroup of primary mRCC patients, female gender or younger age was not associated with improved OS, whereas prior nephrectomy and/or at least 1 targeted therapy was a significant predictor for longer OS (Table 3). Thus, median adjusted OS for the primary mRCC patients who received nephrectomy only, targeted therapy only, or nephrectomy plus targeted therapy was $14.0,12.0$, and 23.0 months, respectively, compared with 4.0 months for those who received neither therapy (Figure 4B).

In the subgroup of elderly mRCC patients, prior nephrectomy or at least 1 targeted therapy was also statistically significantly associated with $48.6 \%$ and $53.0 \%$ reduction, respectively, in the risk of death (Table 3). Median OS was 14.0 months in elderly mRCC patients who received at least 1 targeted therapy compared with 5.0 months in those who did not receive such therapy (Figure 4C). Similarly, in the 

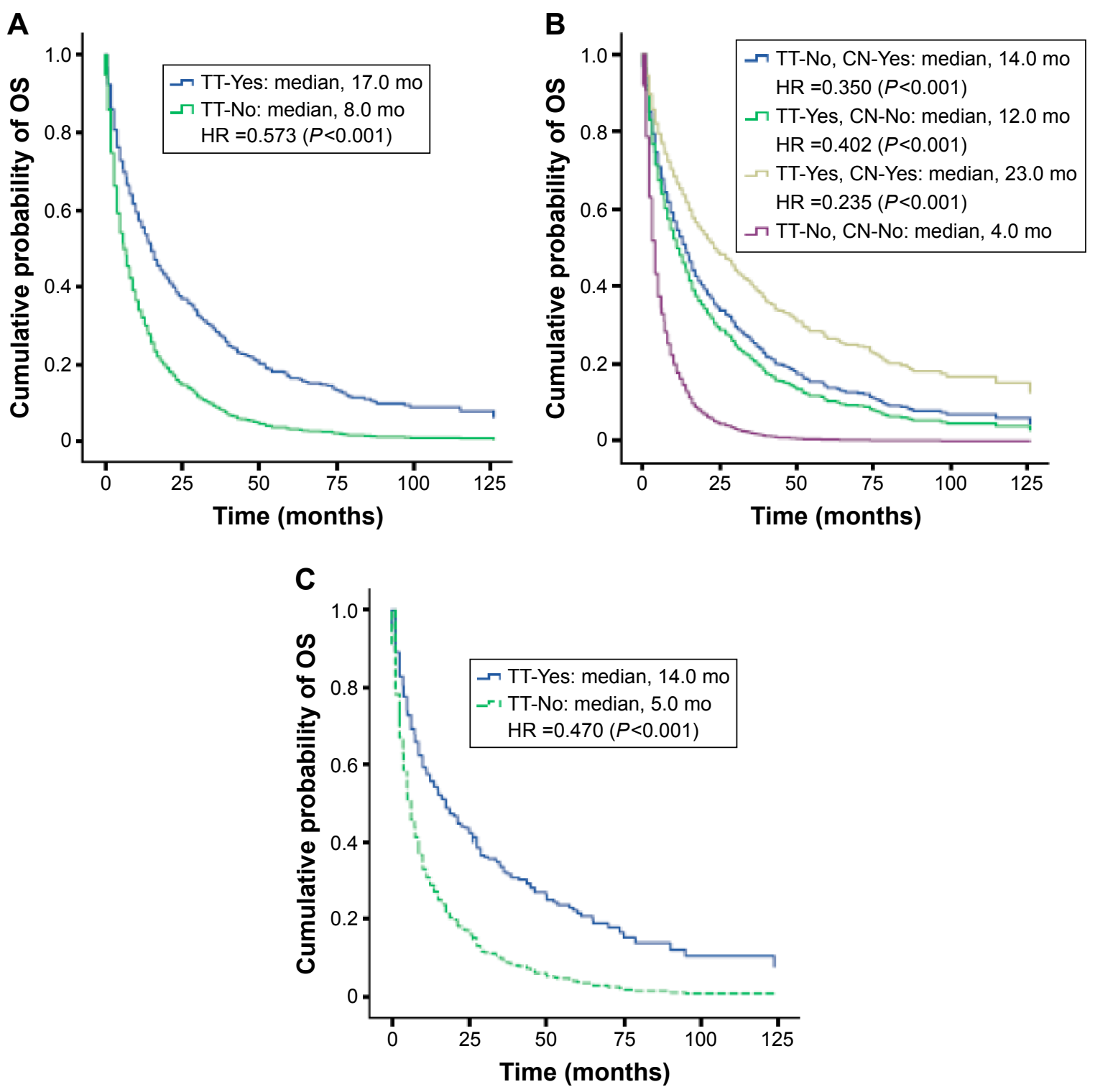

Figure 4 Kaplan-Meier estimates of OS adjusted by multivariate Cox proportional hazards regression analysis in Norwegian patients diagnosed with: (A) mRCC, by TT; (B) primary mRCC, by CN only, TT only, both CN and TT, and neither treatment; and (C) mRCC, who were aged 75 years or older, by TT.

Abbreviations: CN, cytoreductive nephrectomy; HR, hazard ratio; mo, months; mRCC, metastatic renal cell carcinoma; OS, overall survival; TT, targeted therapy.

subgroup of mRCC patients with clear cell histology, those who received at least 1 targeted therapy or prior nephrectomy had a significantly $(P<0.001)$ reduced risk of death compared with those who received neither therapy.

The multivariate regression analysis by county revealed significant regional variations in $\mathrm{OS}$ in both the RCC and mRCC populations, with a maximum estimated difference in HR of $73 \%$ (RCC) or $76 \%$ (mRCC) between the best and worst counties (Table S2).

\section{Discussion}

This study utilized population-based data to determine the impact of targeted therapy in patients with RCC in a real-world setting. Using data from 2 Norwegian national health registries, we observed a positive evolution in RCC and $\mathrm{mRCC}$ management practices and patient prognoses between the years 2002 and 2011. In our analyses, we found a substantial increase not just in the proportion of Norwegian patients receiving therapy for $\mathrm{mRCC}$, but specifically in those using targeted therapies, including several lines of therapy. Improvements in survival were seen in patients diagnosed after the introduction of targeted therapies compared with the pre-targeted therapy era, as evidenced by a significant increase in OS over time in both the RCC and $\mathrm{mRCC}$ populations. In the RCC population, median OS was 92 months with a steady incremental improvement over time. In the mRCC 
population, median OS was 11.0 months and improved from 9.0 months in 2002-2005 to 12.0 months in 2006-2008, and then to 14.0 months in 2009-2011. This study suggests that for $\mathrm{mRCC}$ patients, active treatments with nephrectomy and targeted therapy are very important factors contributing to longer survival. Patients with $\mathrm{mRCC}$ who received at least 1 targeted therapy had a 9-month longer median OS than those who did not, and this magnitude of difference was also evident in patients with higher age (age $75+$ years). For patients with primary $\mathrm{mRCC}$ who received both nephrectomy and targeted therapy, median OS was as high as 23 months.

The multivariate analysis showed that history of nephrectomy, gender, age, and year of diagnosis were factors significantly associated with longer OS in RCC patients. These factors have previously been identified as predictors for survival in other population-based studies in this patient group. ${ }^{19-21}$ Nephrectomy remains the standard of care for RCC, and potentially a cure, and its use has been steady at $\sim 83 \%$ over the study period.

It is not surprising that RCC patients who were younger at diagnosis, and thus likely healthier with fewer comorbidities, would be at lower risk of death, but it is unclear why female gender was associated with longer survival. One possible explanation is that female RCC patients presented with smaller tumors of lower grade than male RCC patients. ${ }^{28}$ Localized disease has been reported as 1 of the 3 strongest predictors of improved OS in RCC, the others being nephrectomy and clear cell histology. ${ }^{19}$

In the multivariate analysis of factors that might impact OS in the mRCC population, administration of at least 1 targeted therapy, of which sunitinib was the most prescribed first-line therapy, was clearly associated with a significantly reduced risk of death (HR 0.573; $P<0.001$ ). Similarly, prior nephrectomy significantly reduced the risk of death (HR $0.463 ; P<0.001$ ) in this population. Importantly, when including both targeted therapy and prior nephrectomy, the multivariate regression analysis no longer showed significant differences in OS among the 3 cohorts of mRCC patients, supporting the contribution of these active treatments in prolonging survival. The importance of nephrectomy in treating $\mathrm{mRCC}$ patients is being prospectively investigated in 2 ongoing trials: the CARMENA (Clinical Trial to Assess the Importance of Nephrectomy) trial, which compares nephrectomy plus sunitinib versus sunitinib alone (ClinicalTrial.gov identifier NCT00930033), and the SURTIME (Immediate Surgery or Surgery After Sunitinib Malate in Treating Patients with Metastatic Kidney Cancer) trial, which is investigating the effect of immediate nephrectomy compared with deferred post-sunitinib nephrectomy (linicalTrial.gov identifier NCT01099423). Since the rate of nephrectomy was rather stable over time at $\sim 65 \%$ among mRCC patients in this study, it is reasonable to conclude that the increase in survival over time was likely driven by increased use of targeted therapy in $\mathrm{mRCC}$ patients who were previously left untreated. This is indeed supported by a substantial decrease in the fraction of $\mathrm{mRCC}$ patients who were untreated, from $94.2 \%$ in 2002 (prior to the introduction of targeted therapy) to $27.6 \%$ in 2011 .

Our findings are consistent with data from national registry and cohort studies in Sweden and Denmark, which also demonstrated significant increases in the use of targeted therapies and associated improvements in OS. ${ }^{21,22}$ In the Swedish population study (the Renal Comparison [RENCOMP]), which compared equivalent time periods to this study (2002-2005 and 2006-2008), median OS improved from 9.6 to 12.4 months in the $\mathrm{mRCC}$ population and from 47.9 months to not reached among the RCC population. ${ }^{21}$ The same strong association between longer survival and cytoreductive nephrectomy or use of targeted therapy was also seen in the Swedish study. In the Danish population study (the Danish Renal Cancer Group [DARENCA]), median OS increased from 11.5 months in 2006 to 17.2 months in 2010 in patients who received active therapy, ${ }^{22}$ but these results did not include a large fraction of untreated patients, for whom median OS was only 3 months. In addition, our study, which spanned up to 2011, included 2 additional newer targeted agents, namely, pazopanib and axitinib, reflecting more up-to-date clinical situations than the other 2 Scandinavian population studies.

Compared with results from typical clinical trials of targeted therapies, median OS for $\mathrm{MRCC}$ patients in these Scandinavian population studies, including this study, is relatively low. However, until $2010,>40 \%$ of mRCC patients in Norway did not receive any form of targeted therapy (Table 2). It is important to consider the number of mRCC patients not receiving treatment within each cohort, which likely reflects the real-world setting, where patients were non-selected and clinical practice varied substantially. With a large fraction of patients untreated, one cannot expect large improvements in median OS. However, judging from median survival and the interquartile range, significant improvements in OS have been achieved that are possibly indicative of long-term survivors on targeted therapies.

Three large studies using US registry data have demonstrated similar positive outcomes following the introduction of targeted therapy. For patients with advanced RCC in 
California, 3-year OS increased from $68.2 \%$ in $1998-2003$ to $74.6 \%$ in $2004-2007(P<0.001) .{ }^{19}$ A study based on the nationwide US Surveillance, Epidemiology and End Results (SEER) database showed a significant improvement in OS for advanced RCC patients treated after, compared with before, the introduction of targeted therapy (median OS: 15 vs 20 months; $P=0.0006) .{ }^{20}$ A recent report utilizing the 2000-2010 SEER research file indicated a significantly reduced risk for death (HR $0.86 ; P<0.01$ ) among patients diagnosed with advanced $\mathrm{RCC}$ in the targeted therapy era compared with pre-targeted therapy era. ${ }^{29}$ However, additional studies may be required to determine the extent to which the use of targeted therapy has contributed to survival improvement.

One advantage of this study over those mentioned earlier is the extended follow-up period, which provided a more mature and robust data set. However, an update to the Swedish RENCOMP study covering years 2009-2012 has recently been presented in which a continued significant improvement in OS was achieved during more recent years of the targeted therapy era. ${ }^{30}$ Another advantage with this study is that in Norway, the drugs in question are dispensed through pharmacies only and are all recorded in the NorPD database utilized in this study, in comparison with Sweden, where drugs may be dispensed through clinics, which go unrecorded in the national registry, thereby potentially leading to an underestimation of the impact of targeted therapy. ${ }^{21}$

Subgroup analyses of the current data set revealed that improvement in OS in the post-targeted therapy era was also observed among primary mRCC patients. A similar trend for improved clinical outcomes after approval of targeted therapy was seen in mRCC patients who were aged 75 years or older. Elderly patients tend to be underrepresented in clinical trials, due to confounding factors such as comorbidities. However, our study indicated that treatment with targeted therapy would likely lead to better clinical outcomes in elderly mRCC patients, consistent with findings reported by others. ${ }^{31-34}$ Although safety and tolerability of targeted agents in elderly patients were not reviewed in our study, others have reported that they were generally similar to those in younger patients. ${ }^{31,33-35}$ Therefore, although retrospective in nature, our study, as well as other available data, supports the clinical benefit of using targeted therapy in elderly mRCC patients.

Subgroup analysis based on RCC histology demonstrated comparable median OS in patients with clear cell or papillary RCC, but a notably longer median OS in patients with chromophobe RCC. Although the result for chromophobe RCC should be interpreted with caution due to the small number of patients, similar results have been reported previously. ${ }^{36,37}$
With increasing numbers of targeted therapies becoming available, more patients received additional lines of therapy in this study. Median OS for mRCC patients who received 1, 2 , and 3 or more lines of therapy was 13,17 , and 33 months, respectively, compared with 8 months for those who did not receive any therapy. This is in line with results from other studies, ${ }^{22,38,39}$ including a retrospective analysis of the International Metastatic RCC Database Consortium database that found median OS for patients who received 1 , 2 , and 3 or more lines of targeted therapy to be 14.9, 21.0, and 39.2 months, respectively. ${ }^{40}$ Together, these data point to the clinical value of administering sequential targeted therapy as a basis for the continuum of care for $\mathrm{mRCC}$ patients and should be the measuring stick for new therapeutic approaches.

In this study, regional differences in survival probability were noted in both RCC and mRCC populations, as seen in the Swedish population-based study. ${ }^{21}$ A similar geographic disparity in survival has been reported for other types of cancer in Norway. ${ }^{23}$ Such findings may largely be attributed to differences in treatment strategy and clinical practice at various institutions throughout Norway, apart from patientand/or cancer-related factors. As such, this type of analysis can be useful as a tool to identify reasons for these relatively large differences observed. To this end, introduction of the National Cancer Pathways initiative may provide a more standardized approach that would ensure equal outcomes across different counties throughout the country.

This study had some limitations, including its retrospective nature. Because well-known prognostic factors such as Memorial Sloan Kettering Cancer Centre ${ }^{41}$ or Heng ${ }^{42}$ risk factors were not recorded in the 2 registries, they could not be included in the survival analyses. Such risk factors could potentially influence whether the individual patient is considered fit for nephrectomy and/or subsequent lines of targeted therapy, resulting in patient selection bias. However, as our study comprises a national cohort of RCC and $\mathrm{mRCC}$, and it can be expected that the risk profile distribution is unchanged over time, this should not have affected the OS estimates in the Kaplan-Meier analysis. Another confounding factor is notable increases in early detection of smaller and lower-grade tumors, which are known to be associated with better clinical outcomes. Since temsirolimus, an intravenous drug, is not dispensed at pharmacies, this TKI was not included in this analysis. Finally, the algorithm used to determine patients with metastatic disease was not without shortcomings and may have included some nonmetastatic patients or, conversely, excluded some metastatic patients. 
In conclusion, population-based studies such as this analysis add further real-life validation to the improved survival outcomes repeatedly observed in RCTs of targeted therapies. OS for Norwegian mRCC patients improved between 2002 and 2011. Although there are likely many contributing factors to the observed increases in OS, this retrospective analysis suggests that targeted therapies have made an important contribution to this improvement. Targeted therapy alone or in combination with nephrectomy provides a significantly reduced risk for death in $\mathrm{mRCC}$ patients, including the elderly. This analysis has revealed that there is still a relatively large fraction of $\mathrm{mRCC}$ patients who do not receive any form of prescribed therapy or treatment limited to just 1 line of targeted therapy, suggesting that there is still room to improve the overall clinical outcome using current treatment options. Further adaptation of treatment sequences and introduction of new treatment modalities should additionally improve the outlook for patients diagnosed with $\mathrm{mRCC}$.

\section{Acknowledgments}

This study was sponsored by Pfizer. The study sponsor was involved in the study design and collection, analysis and interpretation of data, writing of the manuscript, and the decision to submit the manuscript for publication. Medical writing support was provided by Andy Gannon and Alice Wareham at ACUMED ${ }^{\circledR}$ (New York, NY, USA), an Ashfield company, part of UDG Healthcare plc, and Mariko Nagashima, PhD, of Engage Scientific Solutions (Southport, CT, USA) and was funded by Pfizer.

\section{Disclosure}

$\mathrm{C}$ Beisland has no disclosures except reimbursement of travel expenses for this study. O Klepp has received a traveling grant from Pfizer supporting presentation of the preliminary data from this study as a poster at the 2015 American Society of Clinical Oncology Genitourinary Cancers Symposium. KM Torgersen, O Solli, and R Sandin are employees of and own stock in Pfizer. J Kowalski is an independent consultant for Pfizer and is responsible for all statistical analyses for this study, for which he received funding. TB Johannesen, U Axcrona, and J Oldenburg have no conflicts of interest.

\section{References}

1. Escudier B, Porta C, Schmidinger M, et al. Renal cell carcinoma: ESMO clinical practice guidelines for diagnosis, treatment and follow-up. Ann Oncol. 2014;25(suppl 3):iii49-iii56.

2. Ljungberg B, Bensalah $\mathrm{K}$, Canfield $\mathrm{S}$, et al. EAU guidelines on renal cell carcinoma: 2014 update. Eur Urol. 2015;67(5):913-924.
3. National Comprehensive Cancer Network. NCCN Clinical Practice Guidelines in Oncology. Kidney Cancer, Version 2.2016. Available from: http://www.nccn.org/professionals/physician_gls/pdf/kidney. pdf. Accessed July 13, 2016.

4. Escudier B, Eisen T, Stadler WM, et al. Sorafenib in advanced clear-cell renal-cell carcinoma. $N$ Engl J Med. 2007;356(2):125-134.

5. Motzer RJ, Hutson TE, Tomczak P, et al. Sunitinib versus interferon alfa in metastatic renal-cell carcinoma. $N$ Engl J Med. 2007;356(2): $115-124$.

6. Motzer RJ, Hutson TE, Cella D, et al. Pazopanib versus sunitinib in metastatic renal-cell carcinoma. N Engl J Med. 2013;369(8):722-731.

7. Rini BI, Escudier B, Tomczak P, et al. Comparative effectiveness of axitinib versus sorafenib in advanced renal cell carcinoma (AXIS): a randomised phase 3 trial. Lancet. 2011;378(9807):1931-1939.

8. Escudier B, Pluzanska A, Koralewski P, et al. Bevacizumab plus interferon alfa-2a for treatment of metastatic renal cell carcinoma: a randomised, double-blind phase III trial. Lancet. 2007;370(9605): 2103-2111.

9. Rini BI, Halabi S, Rosenberg JE, et al. Bevacizumab plus interferon alfa compared with interferon alfa monotherapy in patients with metastatic renal cell carcinoma: CALGB 90206. J Clin Oncol. 2008; 26(33):5422-5428.

10. Hudes G, Carducci M, Tomczak P, et al. Temsirolimus, interferon alfa, or both for advanced renal-cell carcinoma. N Engl J Med. 2007;356(22): 2271-2281.

11. Motzer RJ, Escudier B, Oudard S, et al. Efficacy of everolimus in advanced renal cell carcinoma: a double-blind, randomised, placebocontrolled phase III trial. Lancet. 2008;372(9637):449-456.

12. Eble JN, Sauter G, Epstein JI, Sesterhenn IA, World Health Organization classification of tumours. Pathology and Genetics of Tumours on the Urinary System and Male Genital Organs. Lyon, France: International Agency for Research on Cancer (IARC) Press; International Academy of Pathology (IAP); 2016. Available from: https://www. iarc.fr/en/publications/pdfs-online/pat-gen/bb7/BB7.pdf. Accessed July 13, 2016.

13. Sankin A, Hakimi AA, Hsieh JJ, Molina AM. Metastatic non-clear cell renal cell carcinoma: an evidence based review of current treatment strategies. Front Oncol. 2015;5:67.

14. Nickerson ML, Jaeger E, Shi Y, et al. Improved identification of Von Hippel-Lindau gene alterations in clear cell renal tumors. Clin Cancer Res. 2008;14(15):4726-4734.

15. Kaelin WG Jr. Treatment of kidney cancer: insights provided by the VHL tumor-suppressor protein. Cancer. 2009;115(10 suppl):2262-2272.

16. Aapro MS, Köhne CH, Cohen HJ, Extermann M. Never too old? Age should not be a barrier to enrollment in cancer clinical trials. Oncologist. 2005;10(3):198-204.

17. Heng DY, Choueiri TK, Rini BI, et al. Outcomes of patients with metastatic renal cell carcinoma that do not meet eligibility criteria for clinical trials. Ann Oncol. 2014;25(1):149-154.

18. Heng DYC, Chi KN, Murray N, et al. A population-based study evaluating the impact of sunitinib on overall survival in the treatment of patients with metastatic renal cell cancer. Cancer. 2009;115(4): 776-783.

19. Shek D, Tomlinson B, Brown M, Brunson A, Pan C-X, Lara PN Jr. Epidemiologic trends in renal cell carcinoma in the cytokine and postcytokine eras: a registry analysis of 28,252 patients. Clin Genitourin Cancer. 2012;10(2):93-98.

20. Vaishampayan UN, Vankayala H, Vigneau FD, et al. The effect of targeted therapy on overall survival in advanced renal cancer: a study of the national surveillance epidemiology and end results registry database. Clin Genitourin Cancer. 2014;12(2):124-129.

21. Wahlgren T, Harmenberg U, Sandström P, et al. Treatment and overall survival in renal cell carcinoma: a Swedish population-based study (2000-2008). Br J Cancer. 2013;108(7):1541-1549.

22. Soerensen AV, Donskov F, Hermann GG, et al. Improved overall survival after implementation of targeted therapy for patients with metastatic renal cell carcinoma: results from the Danish Renal Cancer Group (DARENCA) Study-2. Eur J Cancer. 2014;50(3):553-562. 
23. Rahimi A, Borgan E, Aagnes B, Møller B. Cancer Survival by County and Health Region in Norway, 2000-2009. Oslo: Cancer Registry of Norway; 2016. Available from: https://www.kreftregisteret.no/ globalassets/cancer_survival_by_county_and_health_region_in_ norway_2000-2009.pdf. Accessed July 13, 2016.

24. Larsen IK, Småstuen M, Johannesen TB, et al. Data quality at the Cancer Registry of Norway: an overview of comparability, completeness, validity and timeliness. Eur J Cancer. 2009;45(7):1218-1231.

25. Norwegian Institute of Public Health [homepage on the Internet]. Norwegian Prescription Database. Oslo, Norway: Norwegian Institute of Public Health (NIPH); 2016. Available from: http://www.norpd.no/. Accessed July 13, 2016.

26. Furu K. Establishment of the nationwide Norwegian prescription database (NorPD) - new opportunities for research in pharmacoepidemiology in Norway. Nor Epidemiol. 2008;18(2):129-136.

27. Norwegian Government Minister of Health and Care Services [webpage on the Internet]. Act of 18 May 2001 No 24 on Personal Health Data Filing Systems and the Processing of Personal Health Data (Personal Health Data Filing System Act). 2006. Available from: https://www.regjeringen.no/en/topics/health-and-care/public-health/ Act-of-18-May-2001-No-24-on-Personal-Health-Data-Filing-Systemsand-the-Processing-of-Personal-Health-Data-Personal-Health-DataFiling-System-Act-/id224129/. Accessed November 9, 2016.

28. Aron M, Nguyen MM, Stein RJ, Gill IS. Impact of gender in renal cell carcinoma: an analysis of the SEER database. Eur Urol. 2008;54(1): $133-140$.

29. Li P, Wong YN, Armstrong K, et al. Survival among patients with advanced renal cell carcinoma in the pretargeted versus targeted therapy eras. Cancer Med. 2016;5(2):169-181.

30. Lindskog M, Wahlgren T, Sandin R, et al. Overall survival (OS) in Swedish RCC patients treated 2000-2012: update of the RENCOMP study. J Clin Oncol. 2015;33(7 suppl):Abstr 413.

31. Hutson TE, Bukowski RM, Rini BI, et al. Efficacy and safety of sunitinib in elderly patients with metastatic renal cell carcinoma. $\mathrm{Br} J$ Cancer. 2014;110(5):1125-1132.

32. Khambati HK, Choueiri TK, Kollmannsberger CK, et al. Efficacy of targeted therapy for metastatic renal cell carcinoma in the elderly patient population. Clin Genitourin Cancer. 2014;12(5):354-358.
33. Porta C, Calvo E, Climent MA, et al. Efficacy and safety of everolimus in elderly patients with metastatic renal cell carcinoma: an exploratory analysis of the outcomes of elderly patients in the RECORD-1 trial. Eur Urol. 2012;61(4):826-833.

34. Zanardi E, Grassi P, Cavo A, et al. Treatment of elderly patients with metastatic renal cell carcinoma. Expert Rev Anticancer Ther. 2016; 16(3):323-334.

35. Procopio G, Bellmunt J, Dutcher J, et al. Sorafenib tolerability in elderly patients with advanced renal cell carcinoma: results from a large pooled analysis. Br J Cancer. 2013;108(2):311-318.

36. Koh Y, Lim HY, Ahn JH, et al. Phase II trial of everolimus for the treatment of nonclear-cell renal cell carcinoma. Ann Oncol. 2013;24(4): 1026-1031.

37. Kroeger N, Xie W, Lee J-L, et al. Metastatic non clear cell renal cell carcinoma treated with targeted therapy agents: characterization of survival outcome and application of the International mRCC Database Consortium criteria. Cancer. 2013;119(16):2999-3006.

38. Hutson T, Nosov D, Tomczak P, et al. Tivozanib vs sorafenib targeted therapy for advanced renal cell carcinoma: final results of a phase III trial (901) and efficacy results of a 2nd line tivozanib extension study (902). J Clin Oncol. 2015;33(15 suppl):Abstr 4557.

39. Vallet S, Pahernik S, Höfner T, et al. Efficacy of targeted treatment beyond third-line therapy in metastatic kidney cancer: retrospective analysis from a large-volume cancer center. Clin Genitourin Cancer. 2015; 13(3): $145-\mathrm{e} 152$.

40. Ko JJ, Choueiri TK, Rini BI, et al. First-, second-, third-line therapy for mRCC: benchmarks for trial design from the IMDC. Br J Cancer. 2014;110(8):1917-1922.

41. Motzer RJ, Bacik J, Murphy BA, Russo P, Mazumdar M. Interferon-alfa as a comparative treatment for clinical trials of new therapies against advanced renal cell carcinoma. J Clin Oncol. 2002;20(1):289-296.

42. Heng DY, Xie W, Regan MM, et al. Prognostic factors for overall survival in patients with metastatic renal cell carcinoma treated with vascular endothelial growth factor-targeted agents: results from a large, multicenter study. J Clin Oncol. 2009;27(34):5794-5799. 


\section{Supplementary materials}
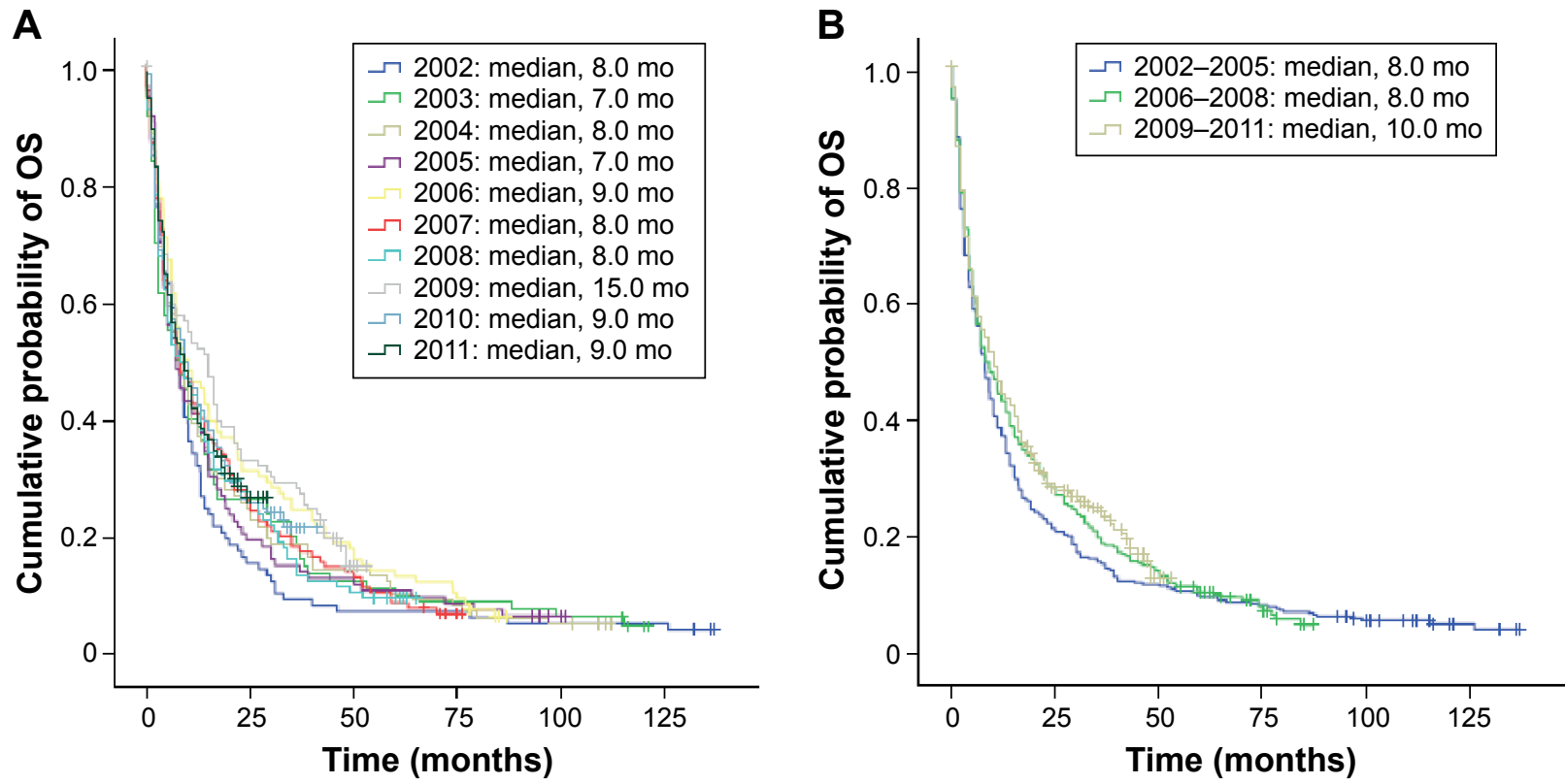

Figure SI Kaplan-Meier estimates of OS in Norwegian patients diagnosed with primary mRCC by (A) year of diagnosis and (B) cohorts. Abbreviations: mo, months; $\mathrm{mRCC}$, metastatic renal cell carcinoma; OS, overall survival.
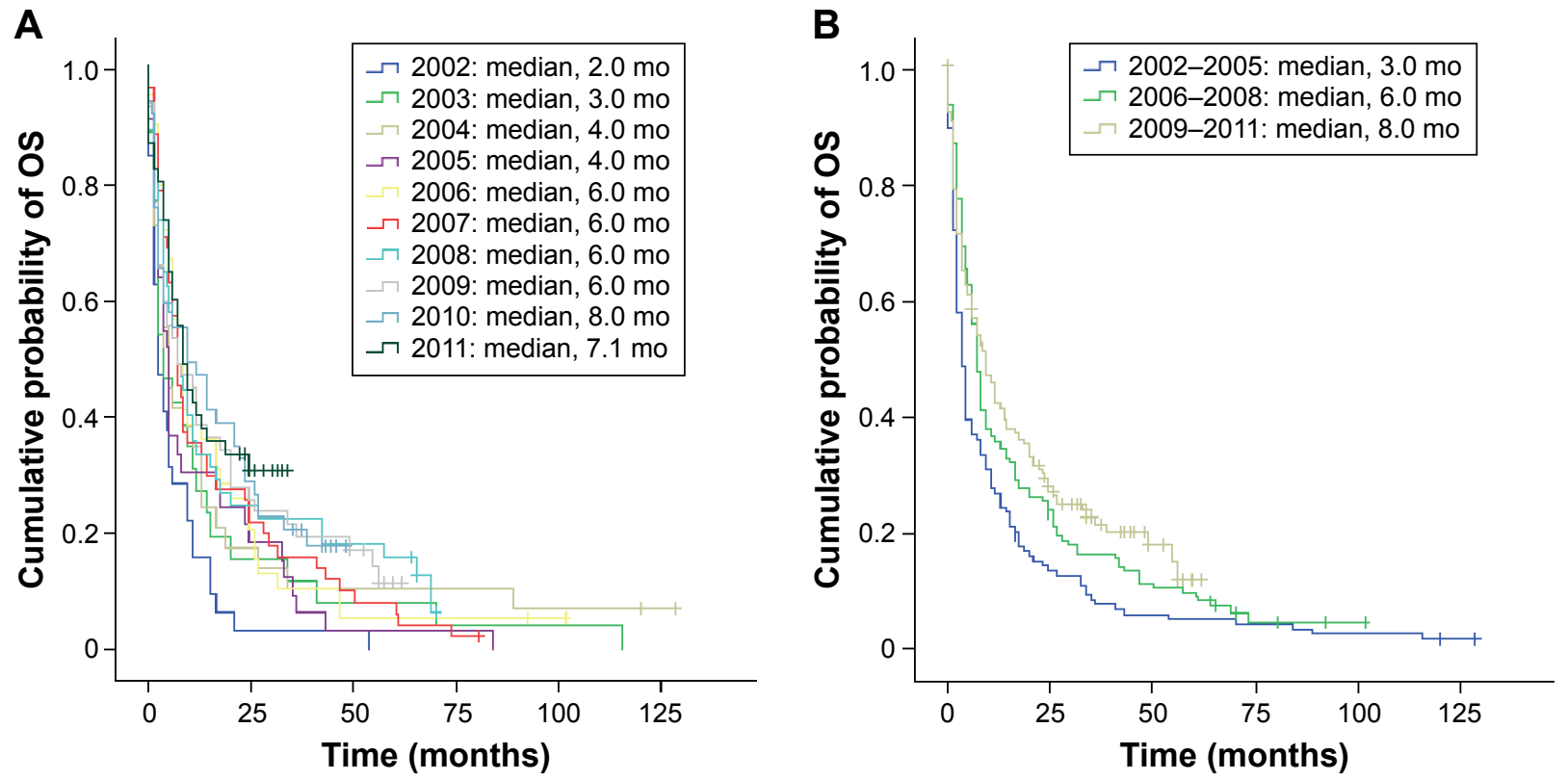

Figure S2 Kaplan-Meier estimates of OS in Norwegian patients diagnosed with mRCC who were aged 75 years or older by (A) year of $\mathrm{mRCC}$ diagnosis and (B) cohorts. Abbreviations: mo, months; $\mathrm{mRCC}$, metastatic renal cell carcinoma; OS, overall survival. 
Table SI Multivariate Cox proportional hazards regression analysis of factors, including line of therapy, predictive for OS in $\mathrm{mRCC}$ patients in Norway diagnosed between 2002 and 2011

\begin{tabular}{|c|c|c|}
\hline \multirow[t]{2}{*}{ Variable } & \multicolumn{2}{|l|}{$\operatorname{mRCC}(n=1,678)$} \\
\hline & $\operatorname{HR}(95 \% \mathrm{CI})^{\mathrm{a}}$ & $P$-value \\
\hline \multicolumn{3}{|l|}{ Year of diagnosis } \\
\hline $2002-2005$ & 1.000 & - \\
\hline 2006-2008 & $0.980(0.856-|.12|)$ & 0.765 \\
\hline 2009-20II & $0.893(0.775-1.030)$ & 0.120 \\
\hline \multicolumn{3}{|l|}{ Gender ${ }^{b}$} \\
\hline Female vs male & $0.887(0.789-0.997)$ & 0.044 \\
\hline \multicolumn{3}{|l|}{ Age, years } \\
\hline$\leq 49$ & 1.000 & - \\
\hline $50-59$ & $0.959(0.764-\mid .202)$ & 0.714 \\
\hline $60-69$ & I.I59 (0.935-I.436) & 0.178 \\
\hline $70-79$ & I.204 (0.968-I.498) & 0.095 \\
\hline$\geq 80$ & $1.304(1.010-1.684)$ & 0.042 \\
\hline \multicolumn{3}{|c|}{ Prior nephrectomy ${ }^{\mathrm{b}}$} \\
\hline Yes vs no & $0.464(0.4 \mid 2-0.522)$ & $<0.001$ \\
\hline \multicolumn{3}{|l|}{ Line of therapy } \\
\hline No line & 1.000 & - \\
\hline I line & $0.7 \mid 3(0.62|-0.8| 8)$ & $<0.001$ \\
\hline 2 lines & $0.574(0.472-0.699)$ & $<0.001$ \\
\hline $3+$ lines & $0.369(0.292-0.466)$ & $<0.001$ \\
\hline
\end{tabular}

Notes: ${ }^{2}$ Adjusted for geographic region. ${ }^{b}$ For binary variables, an $\mathrm{HR}<\mathrm{I}$ equates to risk reduction for the first category and an $\mathrm{HR}>\mathrm{I}$ equates to risk reduction for the second category.

Abbreviations: $\mathrm{Cl}$, confidence interval; $\mathrm{HR}$, hazard ratio; $\mathrm{mRCC}$, metastatic renal cell carcinoma; $\mathrm{OS}$, overall survival.

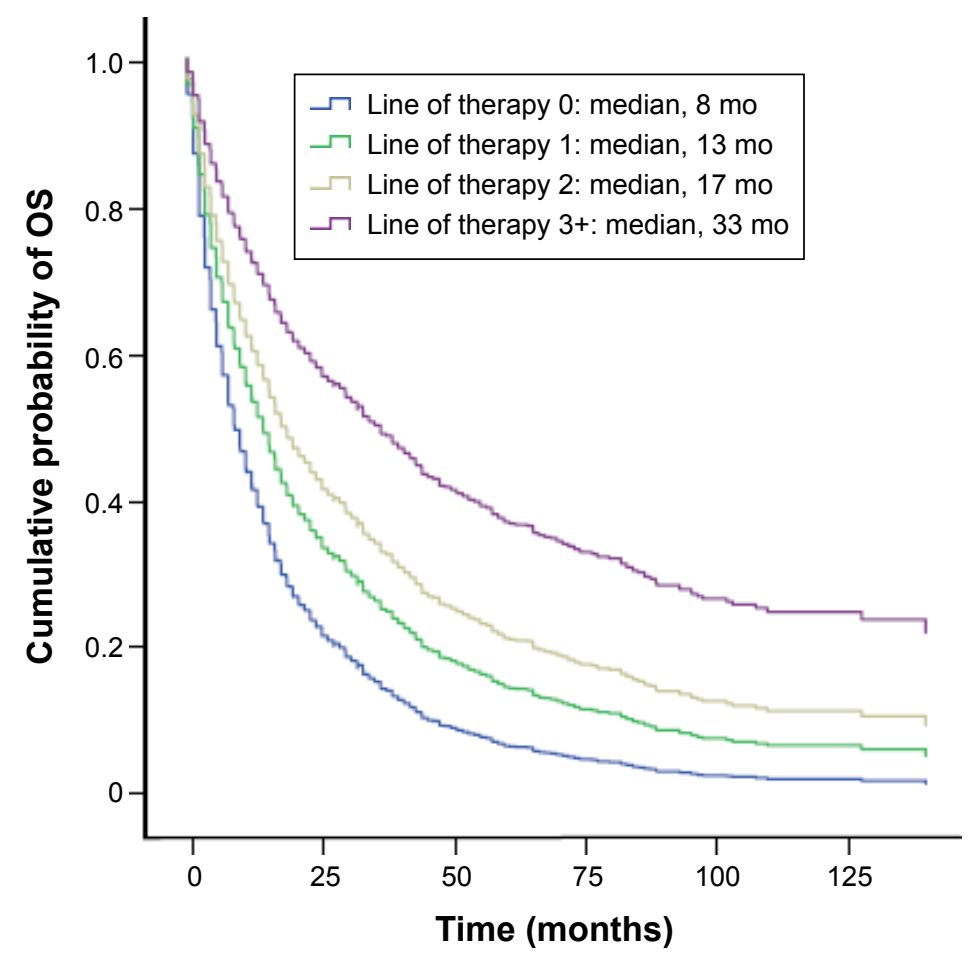

Figure S3 Kaplan-Meier estimates of OS in Norwegian patients diagnosed with mRCC by line of therapy.

Abbreviations: mo, months; mRCC, metastatic renal cell carcinoma; OS, overall survival. 
Table S2 Multivariate Cox proportional hazards regression analysis by region for OS in RCC and mRCC patients in Norway diagnosed between 2002 and 2011

\begin{tabular}{|c|c|c|c|c|}
\hline \multirow[t]{2}{*}{ Regions } & \multicolumn{2}{|l|}{$\operatorname{RCC}(n=5,463)$} & \multicolumn{2}{|l|}{$\operatorname{mRCC}(n=I, 678)$} \\
\hline & HR $(95 \% \mathrm{Cl})^{\mathrm{a}}$ & $P$-value & $\operatorname{HR}(95 \% \mathrm{CI})^{\mathrm{a}}$ & $P$-value \\
\hline Østfold & 1.000 & - & 1.000 & - \\
\hline Akershus & $0.786(0.644-0.958)$ & 0.017 & $0.924(0.709-1.206)$ & 0.563 \\
\hline Hedmark & $0.964(0.762-1.219)$ & 0.757 & $1.156(0.850-1.574)$ & 0.356 \\
\hline Oppland & $0.715(0.555-0.922)$ & 0.010 & $\mathrm{I} .077$ (0.777-I.493) & 0.657 \\
\hline Buskerud & $0.964(0.768-1.210)$ & 0.751 & $1.205(0.885-1.642)$ & 0.236 \\
\hline Vestfold & $0.858(0.679-1.083)$ & 0.198 & $0.969(0.720-1.306)$ & 0.838 \\
\hline Telemark & $0.972(0.762-\mid .24 I)$ & 0.820 & $0.993(0.716-1.377)$ & 0.967 \\
\hline Aust-Agder & I.088 (0.768-I.540) & 0.635 & $1.447(0.952-2.199)$ & 0.084 \\
\hline Vest-Agder & $0.721(0.547-0.950)$ & 0.020 & $0.962(0.665-1.393)$ & 0.838 \\
\hline Rogaland & $0.925(0.753-1.135)$ & 0.453 & I.I $88(0.897-1.573)$ & 0.230 \\
\hline Hordaland & $0.718(0.583-0.885)$ & 0.002 & $0.945(0.717-1.246)$ & 0.690 \\
\hline Sogn og fjordane & $0.943(0.694-1.282)$ & 0.709 & I.I IO (0.734-I.679) & 0.620 \\
\hline Møre og Romsdal & $0.628(0.496-0.795)$ & $<0.001$ & $0.966(0.7 \mid 0-1.313)$ & 0.824 \\
\hline Sør-Trøndelag & $0.632(0.503-0.795)$ & $<0.001$ & $0.820(0.598-1.123)$ & 0.216 \\
\hline Nord-Trøndelag & $0.653(0.486-0.876)$ & 0.004 & I.I 45 (0.792-1.654) & 0.471 \\
\hline Nordland & $1.030(0.833-1.274)$ & 0.784 & I.024 (0.775-I.354) & 0.865 \\
\hline Troms & $0.909(0.689-1.199)$ & 0.499 & $0.910(0.629-1.316)$ & 0.616 \\
\hline Finnmark & $0.874(0.627-1.217)$ & 0.425 & $1.209(0.786-1.858)$ & 0.388 \\
\hline Oslo & $0.892(0.73|-| .088)$ & 0.261 & $1.078(0.823-1.413)$ & 0.585 \\
\hline
\end{tabular}

Note: aRegional estimates of HR that were adjusted for in the analysis for the mRCC model.

Abbreviations: $\mathrm{Cl}$, confidence interval; $\mathrm{HR}$, hazard ratio; $\mathrm{mRCC}$, metastatic renal cell carcinoma; OS, overall survival; RCC, renal cell carcinoma.

\section{Publish your work in this journal}

OncoTargets and Therapy is an international, peer-reviewed, open access journal focusing on the pathological basis of all cancers, potential targets for therapy and treatment protocols employed to improve the management of cancer patients. The journal also focuses on the impact of management programs and new therapeutic agents and protocols on

\section{Dovepress}

patient perspectives such as quality of life, adherence and satisfaction. The manuscript management system is completely online and includes a very quick and fair peer-review system, which is all easy to use. Visit http://www.dovepress.com/testimonials.php to read real quotes from published authors. 